\title{
Endothelin and vasopressin influence splanchnic blood flow distribution during and after cardiopulmonary bypass
}

\author{
Hagen Bomberg, MD, ${ }^{\text {a } B e n j a m i n ~ B i e r b a c h, ~ M D, ~},{ }^{\text {ab }}$ Stephan Flache, MD, ${ }^{\mathrm{a}}$ Isabell Wagner, ${ }^{\mathrm{a}}$ Lena Gläser, ${ }^{\mathrm{a}}$ \\ Heinrich V. Groesdonk, MD, ${ }^{a}$ Michael D. Menger, MD, ${ }^{c}$ and Hans-Joachim Schäfers, MD ${ }^{a}$
}

\begin{abstract}
Objective: Gastrointestinal blood flow can be compromised during and after cardiopulmonary bypass. Endothelin has been shown to be involved in the intestinal microcirculatory disturbance of sepsis. The aim of the present study was to analyze the involvement of the endothelin system on intestinal blood flow regulation during cardiopulmonary bypass and the effect of vasopressin given during cardiopulmonary bypass.
\end{abstract}

\begin{abstract}
Methods: A total of 24 pigs were studied in 4 groups $(n=6)$ : group I, sham; group II, ischemia/reperfusion with 1 hour of superior mesenteric artery occlusion; group III, cardiopulmonary bypass for 1 hour; and group IV, 1 hour of cardiopulmonary bypass plus vasopressin administration, maintaining the baseline arterial pressure. All the pigs were reperfused for 90 minutes. During the experiment, the hemodynamics and jejunal microcirculation were measured continuously. The jejunal mucosal expression of endothelin- 1 and its receptor subtypes A and B were determined using polymerase chain reaction.
\end{abstract}

Results: During cardiopulmonary bypass, superior mesenteric artery flow was preserved but marked jejunal microvascular impairment occurred compared with baseline (mucosal capillary density, $192.2 \pm 5.4$ vs $150.8 \pm 5.1 \mathrm{~cm} / \mathrm{cm}^{2} ; P=.005$; tissue blood flow, $501.7 \pm 39.3$ vs $\left.332.3 \pm 27.9 \mathrm{AU} ; P=.025\right)$. The expression of endothelin- 1 after cardiopulmonary bypass ( $3.2 \pm 0.4 \mathrm{vs} 12.2 \pm 0.8 \mathrm{RQ}, P=.006)$ and endothelin subtype A $(0.7 \pm 0.2$ vs $2.4 \pm 0.6 \mathrm{RQ} ; P=.01)$ was significantly increased compared to the sham group. Vasopressin administration during cardiopulmonary bypass led to normal capillary density $(189.9 \pm 3.9$ vs $178.0 \pm 6.3 ; P=.1)$ and tissue blood flow $(501.7 \pm 39.3$ vs $494.7 \pm 44.4 \mathrm{AU} ; P=.4)$ compared with baseline. The expression of endothelin-1 ( $3.2 \pm 0.4$ vs $1.8 \pm 0.3 \mathrm{RQ} ; P=.3)$ and endothelin subtype A $(0.7 \pm 0.2$ vs $0.9 \pm 0.2 \mathrm{RQ}$; $P=.5$ ) was not different from the sham group.

Conclusions: Cardiopulmonary bypass leads to microvascular impairment of jejunal microcirculation, which is associated with the upregulation of endothelin-1 and endothelin subtype A. The administration of vasopressin minimizes these cardiopulmonary bypass-associated alterations. (J Thorac Cardiovasc Surg 2013;145:539-47)

The incidence of gastrointestinal complications after cardiac surgery with cardiopulmonary bypass (CPB) has been reported to range from $1 \%$ to $3 \% .^{1,2}$ Nonocclusive mesenteric ischemia (NOMI) is the most dreaded of these complications with mortality rates of up to $90 \% .^{1,2}$

It is considered an extreme reduction or maldistribution of splanchnic blood flow. ${ }^{1}$ NOMI is a known consequence

\footnotetext{
From the Department of Thoracic and Cardiovascular Surgery, ${ }^{a}$ University Hospital of Saarland, Homburg/Saar, Germany; Department of Thoracic and Cardiovascular Surgery, ${ }^{\mathrm{b}}$ University Hospital Schleswig-Holstein, Campus Kiel, Kiel, Germany; and Institute for Clinical and Experimental Surgery, ${ }^{\mathrm{c}}$ University Hospital of Saarland, Homburg/Saar, Germany.

The study was supported by a HOMFOR grant (Homburger Forschungsförderungsprogramm der Medizinischen Fakultät der Universität des Saarlandes) of the University of Saarland and did not receive any support from industry. The foundation had no influence on study design, collection, analysis and interpretation of data. Disclosures: Authors have nothing to disclose with regard to commercial support. H.B. and B.B. contributed equally to this work.

Received for publication Dec 28, 2011; revisions received Feb 13, 2012; accepted for publication March 12, 2012; available ahead of print May 2, 2012.

Address for reprints: Hans-Joachim Schäfers, MD, Department of Thoracic and Cardiovascular Surgery, University Hospital Saarland, Kirrbergerstrasse 1, Homburg/ Saar 66421, Germany (E-mail: h-j.schaefers@uks.eu).

$0022-5223 / \$ 36.00$

Copyright (c) 2013 by The American Association for Thoracic Surgery doi:10.1016/j.jtcvs.2012.03.014
}

of low cardiac output ${ }^{1,2}$ and sepsis. ${ }^{3}$ The endothelin (ET) system has been shown to be involved in sepsis-related NOMI. ${ }^{4}$ If NOMI occurs, it commonly affects ileum and distal jejunum most severely. ${ }^{1}$

The clinical risk factors for the development of mesenteric ischemia are hypovolemic shock, ${ }^{1,2}$ severe heart failure and cardiogenic shock, ${ }^{1,2}$ administration of $\alpha$-adrenergic drugs, ${ }^{1,2,5}$ or the use of an intra-aortic balloon pump. ${ }^{1,2}$ The evidence regarding vasoconstrictors is mixed. Catecholamines acting by way of the $\alpha$-adrenoceptors have been proposed to have a negative effect on small bowel microcirculation after $\mathrm{CPB},{ }^{5,6}$ a positive effect in sepsis, ${ }^{3,7}$ and no effect in normal animals. ${ }^{8}$ The stimulation of $\beta$-receptors, however, has been shown to increase intestinal oxygen consumption. ${ }^{9}$ Vasopressin, being independent of adrenoceptors, has been found to decrease intestinal mucosal perfusion after $\mathrm{CPB}^{10}$ and in sepsis ${ }^{11,12}$; it has also been reported to normalize intestinal blood flow in septic shock. ${ }^{7}$

The reduction of jejunal tissue blood flow during CPB has already been documented using laser Doppler or microsphere techniques. ${ }^{5,13}$ Nonetheless, the question remains of whether a specific pathophysiologic mechanism predisposes cardiac surgical patients to the occurrence of 


$$
\begin{aligned}
& \text { Abbreviations and Acronyms } \\
& \begin{aligned}
\mathrm{CPB} & =\text { cardiopulmonary bypass } \\
\mathrm{ET} & =\text { endothelin } \\
\mathrm{ET}-1 & =\text { endothelin- } 1 \\
\mathrm{ET}_{\mathrm{A}} & =\text { ET receptor A } \\
\mathrm{ET}_{\mathrm{B}} & =\mathrm{ET} \text { receptor } \mathrm{B} \\
\mathrm{NOMI} & =\text { nonocclusive mesenteric ischemia } \\
\mathrm{SMA} & =\text { superior mesenteric artery } \\
\mathrm{SVR} & =\text { systemic vascular resistance }
\end{aligned}
\end{aligned}
$$

NOMI (ie, impairment of splanchnic blood flow beyond the phase of extracorporeal circulation).

We decided to study the effects of extracorporeal circulation with and without vasopressor support on mesenteric perfusion in an animal model. To avoid the differential effects of catecholamines on the $\alpha$ - and $\beta$-receptors, we chose vasopressin for this experiment. Because the ET system has found to be involved in the regulation of splanchnic blood flow in septic shock, ${ }^{4}$ we particularly focused on ET-1 and ET receptor expression.

\section{METHODS}

A total of 24 domestic pigs with a body weight of 28 to $32 \mathrm{~kg}$ were used for the experiments. The governmental animal care committee approved the present study.

All pigs in the present study received humane care in compliance with the Principles of Laboratory Animals, formulated by the National Society for Medical Research, and the Guide for the Care and Use of Laboratory Animal Resource, published by the National Institutes of Health (Bethesda, Md).

\section{Animal Preparation}

The pigs were provided a 5-day diet, followed by fasting for 48 hours, with free access to water to minimize the gastrointestinal tract contents. They were premedicated with ketamin $(15 \mathrm{mg} / \mathrm{kg})$, azaperon $(3 \mathrm{mg} / \mathrm{kg})$, atropine sulfate $(0.5 \mathrm{mg})$, and midazolame $(15 \mathrm{mg})$ injected intramuscularly. Anesthesia was induced with sodium-thiopental $(3 \mathrm{mg} / \mathrm{kg})$ and piritramide $(7.5 \mathrm{mg})$, given intravenously. The pigs were intubated and placed on mechanical ventilation, with a fraction of inspired oxygen of 0.3 . Anesthesia was maintained by infusion of sodium-thiopental $(0.4-0.5 \mathrm{mg} / \mathrm{kg} / \mathrm{h})$ and piritramide $(0.25-0.5 \mathrm{mg} / \mathrm{kg} / \mathrm{h})$. Fluid replacement by full electrolyte solution (Sterofundin; B. Braun, Melsungen, Germany) at a rate of $10 \mathrm{~mL} / \mathrm{kg} / \mathrm{h}$ was given. Intraoperative blood loss was replaced by gelatine solution (Gelafundin, B. Braun). The body temperature was maintained at $37.5^{\circ} \mathrm{C}$ by heating.

\section{Animal Instrumentation}

Catheters were introduced in both femoral arteries, and a pulmonary artery catheter was inserted by way of femoral vein access. After a median laparotomy, a urinary catheter was inserted, and the superior mesenteric artery (SMA) was dissected. A transit-time Doppler flow meter (Medistim ASA, Oslo, Norway) and a tourniquet were passed around the vessel. A catheter was introduced into the superior mesenteric vein.

A distal jejunal laser Doppler fluxmetry probe was sutured on the serosal surface approximately $3 \mathrm{~m}$ distal to the ligament of Treitz using 4 interrupted stitches. The tissue was illuminated with coherent laser light for determination of the mucosal blood flow $(830 \mathrm{~nm}$ and $30 \mathrm{~mW})$ and white light for tissue oxygenation (500-800 $\mathrm{nm}$ and $20 \mathrm{~W}$ ) from a combined diode (fiber separation of $1 \mathrm{~mm}$ ) through a fiberoptic light guide (O2C, Lea Medizintechnik, Giessen, Germany). An intravital microscope (Imaging Unit $[10 \times]$ with LED FA series, MicroVision Medical, Amsterdam, The Netherlands) was placed on the serosal surface 20 to $30 \mathrm{~cm}$ from the laser Doppler probe. Sternotomy was performed, and a left atrial catheter was inserted.

\section{Study Protocol}

The 24 pigs were randomized to 4 groups $(n=6)$ : group I, sham; group II, ischemia/reperfusion (the SMA was occluded for 1 hour followed by 90 minutes of reperfusion); group III, normothermic nonpulsatile CPB for 1 hour followed by 90 minutes of post-CPB perfusion; and group IV, normothermic nonpulsatile $\mathrm{CPB}$ for 1 hour with continuous infusion of vasopres$\sin (0.006 \pm 0.0003 \mathrm{U} / \mathrm{min} / \mathrm{kg})$ for 50 minutes to maintain the mean arterial pressure at the baseline level followed by 90 minutes of post-CPB perfusion. The vasopressin infusion was stopped 10 minutes before discontinuation of CPB and aortic decannulation.

\section{CPB Setup}

After obtaining baseline measurements in groups III (CPB) and IV (CPB plus vasopressin), heparin (500 U/kg) was administered, and the pigs were connected to extracorporeal circulation using ascending aortic and right atrial cannulation. A membrane oxygenator (Quadrox, Jostra, Hirrlingen, Germany) was used. The circuit was primed with $500 \mathrm{~mL}$ full electrolyte solution (Sterofundin, B. Braun) and $500 \mathrm{~mL}$ gelatine solution (Gelafundin, B. Braun). Normothermia was maintained throughout the experiment. The pump flow was adjusted to the baseline cardiac output. After discontinuation of right atrial cannulation, heparin was antagonized with protamin sulphate $(500 \mathrm{U} / \mathrm{kg})$.

\section{Measurements}

The mean arterial blood pressure, central venous pressure, and left atrial pressure were measured continuously. Cardiac output was measured using a continuous thermodilution method (Swan-Ganz continuous cardiac output, mixed venous oxygen saturation monitoring catheter; Edwards Lifescience, Pullach, Germany). SMA blood flow, tissue oxygenation, and mucosal blood flow were measured continuously. Arterial and mesenteric vein blood samples were taken at defined points: baseline, ischemia/CPB 20 minutes, reperfusion 2 minutes, reperfusion 30 minutes, reperfusion 60 minutes, and reperfusion 90 minutes. Vessel density was recorded at the corresponding points and at ischemia/CPB 50 minutes. Systemic vascular resistance (SVR) was calculated as (mean arterial blood pressure - central venous pressure)/cardiac output.

\section{Intravital Microscopy}

Microscopic images were obtained using a mobile intravital microscope (MicroVision Medical), recorded on video (50 Hz; Panasonic, Osaka, Japan), and subsequently analyzed off-line. The capillary diameters were determined using a computer-assisted image analysis system (CapImage; Zeintl Software, Heidelberg, Germany). The functional capillary density was measured as the length of the perfused capillaries per observation field and expressed in centimeters per square centimeters.

\section{Clinical Chemistry Analysis}

ET-1 and lactate were determined in plasma from the arterial and mesenteric venous blood samples (Assay Designs, Immunoassay Kit, catalog no. 900-020A; ABL-System 615, Radiometer, Copenhagen, Denmark).

\section{RNA Extraction and cDNA Synthesis}

At the end of the experiment, biopsies were obtained from the jejunum (close to the measurement of laser Doppler flow) and femoral muscle. 
The specimens were immediately frozen in liquid nitrogen and stored at $-80^{\circ} \mathrm{C}$ until analysis. The total cellular RNA of the jejunal mucosa was isolated using the Qiagen RNeasy Mini Reagent Set (RNeasy Mini Kit No. 74104; Qiagen, Hilden, Germany). The muscle total cellular RNA was isolated using the Qiagen RNeasy Mini Reagent Set (RNeasy Fibrous Tissue Mini Kit No. 74704; Qiagen) according to the manufacturer's recommendations. RNA preparation and handling was performed in a laminar flow hood under RNAse free conditions. The RNA concentration and purity was determined by spectrophotometry. The RNA concentration was greater than $100 \mathrm{ng} / \mu \mathrm{L}$, and the solution was stored at $-80^{\circ} \mathrm{C}$ until further analysis. The purified RNA was transcribed into cDNA in a reverse transcriptasepolymerase chain reaction (PCR). For the cDNA synthesis, the TaqMan Reverse Transcription Reagents Kit (No. N808-0234; Applied Biosystems, Darmstadt, Germany) was used.

\section{Real-Time PCR}

TaqMan real-time quantitative PCR amplification reactions were performed in a StepOne Plus Real-Time PCR System (Applied Biosystems). Each preparation consisted of $10 \mu \mathrm{L}$ TaqMan Gene Expression Master Mix (TaqMan Gene Expression Master Mix No. 4369016; Applied Biosystems), $1 \mu \mathrm{L}$ TaqMan Gene Expression Assay (TaqMan Gene Expression Assay, endothelin-1 [Ss03392453_m1], endothelin receptor A [Ss03394412_m1], endothelin receptor B [Ss03379833_u1], HPRT1 [Ss03388274_m1]; Applied Biosystems), $2 \mu \mathrm{L}$ sample (each with $25 \mathrm{ng}$ cDNA) and $7 \mu \mathrm{L}$ distilled water. The endogenous control was the HPRT1 housekeeping gene.

The complete amplification process contained 45 cycles. All TaqMan PCR data were documented using SDS software (Applied Biosystems).
Linear regression and correlation analysis of real-time PCR amplification data were performed using SDS software (Applied Biosystems). The gene expression was analyzed using the relative quantification approach (Applied Biosystems). A ratio of target tissue and muscle tissue was calculated (RQ). ${ }^{14}$ The quantity calculated for the target subunit was normalized with HPRT1 as the endogenous control. The normalized value of the control (sham) group was taken as the calibrator to calculate the relative expression levels of the target genes in the experimental groups.

\section{Statistical Analysis}

The data are presented as the mean \pm standard error of the mean. Statistical analysis was performed with SigmaStat, version 3.1 (Jandel Scientific, San Rafael, Calif). The statistical significance of the changes from baseline within each group was tested with analysis of variance for repeated measurements and the post hoc test. Differences among the groups were analyzed using 1-way analysis of variance, followed by a post hoc analysis, including the correction of $\alpha$-error according to Bonferroni to compensate for multiple comparisons. If the values did not show a normal distribution, analysis of variance for nonparametric values (Kruskal-Wallis test) was used with the multiple comparison method (Dunn or Bonferroni method). Statistical significance was accepted at an error probability of $P \leq .05$.

\section{RESULTS}

\section{Hemodynamic Parameters}

In group I, all measured parameters remained constant throughout the experiment (Figure 1 and Table 1).
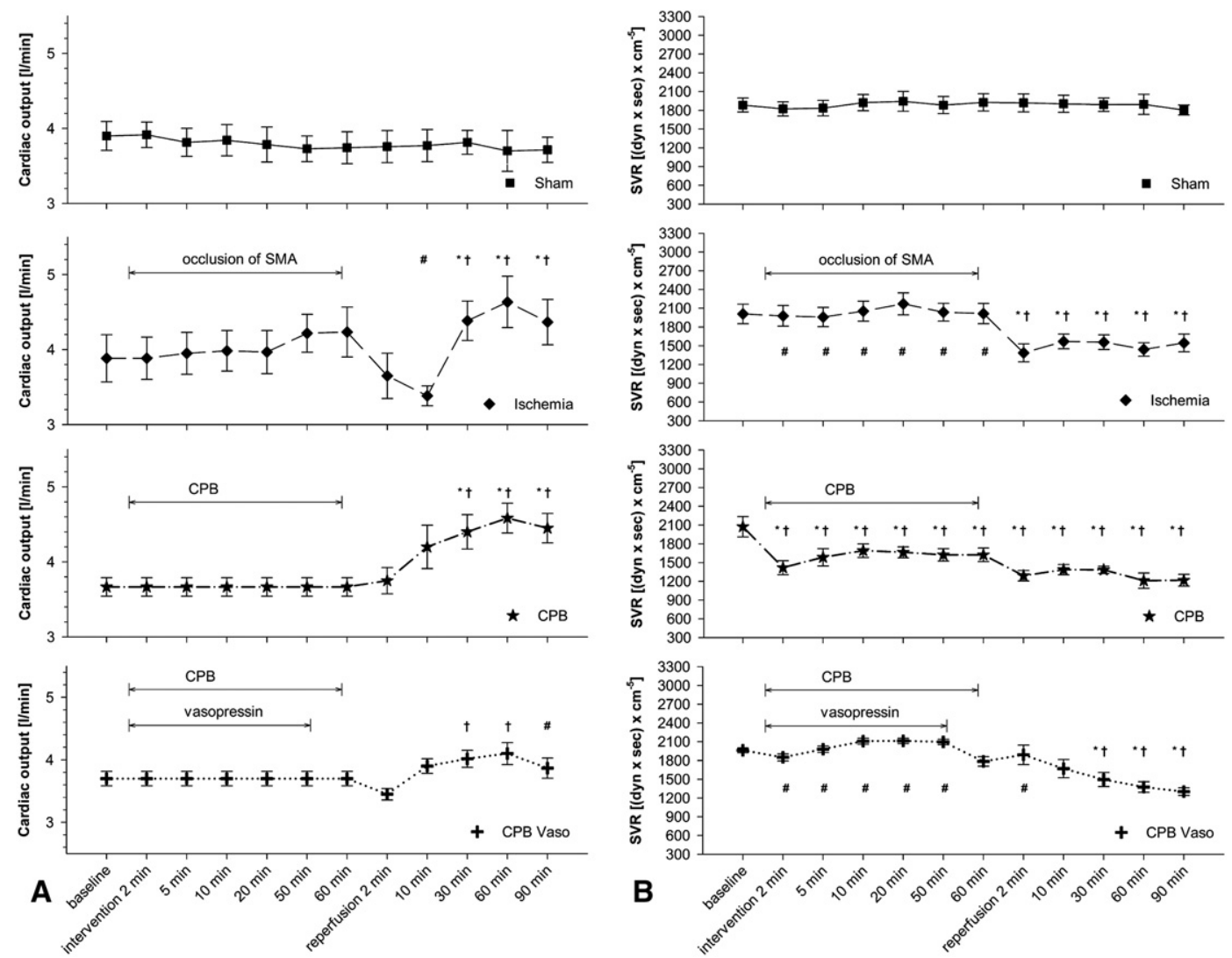

FIGURE 1. A, Cardiac output (L/min) and (B) systemic vascular resistance $(S V R)\left[(\mathrm{dyn} \times \mathrm{sec}) \times \mathrm{cm}^{-5}\right]$. Intervention: 1-hour occlusion of the superior mesenteric artery $(S M A)$ or cardiopulmonary bypass $(C P B) . * P<.05$ vs sham group; $\dagger P<.05$ vs baseline; $\# P<.05$ vs CPB group. Vaso, Vasopressin. 
TABLE 1. Blood analysis, jejunal capillary density, and oxygen saturation

\begin{tabular}{|c|c|c|c|c|c|c|c|c|}
\hline \multirow[b]{2}{*}{ Variable } & \multirow[b]{2}{*}{ Baseline } & \multicolumn{3}{|c|}{ Intervention (min) } & \multicolumn{4}{|c|}{ Reperfusion (min) } \\
\hline & & 20 & 50 & 60 & 2 & 30 & 60 & 90 \\
\hline \multicolumn{9}{|c|}{ Capillary density $\left(\mathrm{cm} / \mathrm{cm}^{2}\right)$} \\
\hline Sham & $196.3 \pm 4.2$ & $196.9 \pm 3.4$ & $197.9 \pm 4.3$ & - & $198.2 \pm 4.3$ & $196.3 \pm 5.2$ & $193.2 \pm 2.8$ & $192.0 \pm 4.8$ \\
\hline Ischemia & $193.0 \pm 2.7$ & $0.0 \pm 0.0^{*}, \dagger, \ddagger$ & $0.0 \pm 0.0^{*}, \dagger, \ddagger$ & - & $145.3 \pm 2.0^{*}, \dagger$ & $169.5 \pm 2.3^{*}, \dagger$ & $134.6 \pm 2.9^{*}, \dagger, \ddagger$ & $124.1 \pm 2.9^{*}, \dagger, \ddagger$ \\
\hline CPB & $192.2 \pm 5.4$ & $150.8 \pm 5.1^{*}, \dagger$ & $143.3 \pm 7.4^{*}, \dagger$ & - & $160.3 \pm 3.2^{*}, \dagger$ & $156.6 \pm 7.4^{*}, \dagger$ & $171.0 \pm 8.3^{*}, \dagger$ & $168.5 \pm 8.5^{*}, \dagger$ \\
\hline CPB, Vaso & $189.6 \pm 3.9$ & $178.0 \pm 6.3 \ddagger$ & $178 \pm 4.4 \ddagger$ & - & $174.2 \pm 4.6^{*}, \dagger$ & $156.2 \pm 9.6^{*}, \dagger$ & $172.0 \pm 6.8^{*}, \dagger$ & $165.8 \pm 4.6^{*}, \dagger$ \\
\hline \multicolumn{9}{|c|}{ Jejunal oxygen saturation (\%) } \\
\hline Sham & $58.3 \pm 4.4$ & $62.4 \pm 2.9$ & $61.8 \pm 2.1$ & $62.2 \pm 2.2$ & $62.0 \pm 2.6$ & $62.3 \pm 2.6$ & $59.7 \pm 2.1$ & $58.7 \pm 2.0$ \\
\hline Ischemia & $61.6 \pm 2.2$ & $10.0 \pm 1.9^{*}, \dagger, \ddagger$ & $8.7 \pm 1.1^{*}, \dagger$ & $8.3 \pm 1.0^{*}, \dagger, \ddagger$ & $57.7 \pm 5.2$ & $73.4 \pm 1.6^{*}, \dagger, \dagger$ & $71.9 \pm 2.0^{*}, \dagger, \ddagger$ & $69.4 \pm 2.1^{*}, \dagger, \ddagger$ \\
\hline $\mathrm{CPB}$ & $64.1 \pm 2.7$ & $48.7 \pm 3.2^{*}, \dagger$ & $47.5 \pm 2.1^{*}, \dagger$ & $47.3 \pm 2.0^{*}, \dagger$ & $64.5 \pm 3.2$ & $62.7 \pm 2.5$ & $59.6 \pm 3.4$ & $57.9 \pm 3.3$ \\
\hline $\mathrm{CPB}$, Vaso & $59.7 \pm 2.5$ & $60.1 \pm 2.5 \ddagger$ & $61.1 \pm 2.4 \ddagger$ & $57.0 \pm 3.1 \ddagger$ & $68.3 \pm 2.3^{*}$ & $68.5 \pm 1.1^{*}$ & $66.6 \pm 2.0^{*}$ & $63.3 \pm 1.6$ \\
\hline \multicolumn{9}{|c|}{ Arterial Hct $(\%)$} \\
\hline Sham & $23.0 \pm 1.1$ & $22.1 \pm 0.9$ & - & - & $22.2 \pm 1.6$ & $20.4 \pm 1.4$ & $20.0 \pm 1.1$ & $19.4 \pm 1.2$ \\
\hline Ischemia & $23.5 \pm 1.2$ & $21.5 \pm 1.1 \ddagger$ & - & - & $22.2 \pm 1.4 \ddagger$ & $20.5 \pm 1.5$ & $20.0 \pm 1.7$ & $18.2 \pm 1.1$ \\
\hline $\mathrm{CPB}$ & $24.5 \pm 1.2$ & $17.8 \pm 0.9^{*}, \dagger$ & - & - & $18.5 \pm 0.5^{*}, \dagger$ & $17.8 \pm 0.7^{*}, \dagger$ & $16.7 \pm 1.0^{*}, \dagger$ & $16.3 \pm 0.6^{*}, \dagger$ \\
\hline CPB, Vaso & $22.5 \pm 1.0$ & $17.3 \pm 0.3^{*}, \dagger$ & - & - & $18.2 \pm 0.9^{*}, \dagger$ & $16.3 \pm 1.0^{*}, \dagger$ & $15.7 \pm 1.0^{*}, \dagger$ & $15.2 \pm 1.0^{*}, \dagger$ \\
\hline \multicolumn{9}{|c|}{ Lactate concentration $\S(\mathrm{mmol} / \mathrm{L})$} \\
\hline Sham & $-0.4 \pm 0.2$ & $-0.2 \pm 0.1$ & - & - & $-0.4 \pm 0.2$ & $-0.2 \pm 0.1$ & $-0.3 \pm 0.1$ & $-0.1 \pm 0.1$ \\
\hline Ischemia & $-0.3 \pm 0.2$ & $-3.5 \pm 0.9 *, \dagger$ & - & - & $-2.1 \pm 0.4^{*}, \dagger$ & $-1.1 \pm 0.2^{*}, \dagger$ & $-0.9 \pm 0.2$ & $-0.4 \pm 0.1$ \\
\hline $\mathrm{CPB}$ & $-0.1 \pm 0.1$ & $-0.3 \pm 0.1$ & - & - & $-0.6 \pm 0.1$ & $0.1 \pm 0.1$ & $-0.3 \pm 0.1$ & $-0.4 \pm 0.1$ \\
\hline CPB, Vaso & $-0.3 \pm 0.1$ & $-0.3 \pm 0.1$ & - & - & $-0.3 \pm 0.1$ & $-0.2 \pm 0.1$ & $-0.6 \pm 0.1$ & $-0.6 \pm 0.1$ \\
\hline \multicolumn{9}{|c|}{ Arterial ET-1 (pg/mL) } \\
\hline Sham & $6.2 \pm 0.5$ & $6.5 \pm 0.5$ & - & - & $6.3 \pm 0.6$ & $6.2 \pm 0.8$ & $5.8 \pm 0.6$ & $6.1 \pm 0.7$ \\
\hline Ischemia & $6.1 \pm 0.5$ & $7.4 \pm 0.5 \dagger$ & - & - & $7.9 \pm 0.5^{*}, \dagger, \ddagger$ & $6.4 \pm 0.5$ & $6.7 \pm 0.5$ & $6.5 \pm 0.4$ \\
\hline $\mathrm{CPB}$ & $6.5 \pm 0.7$ & $6.5 \pm 0.4$ & - & - & $6.2 \pm 0.6$ & $6.4 \pm 0.4$ & $6.4 \pm 0.5$ & $6.1 \pm 0.4$ \\
\hline CPB, Vaso & $6.5 \pm 0.7$ & $6.5 \pm 0.7$ & - & - & $6.3 \pm 0.6$ & $6.4 \pm 0.6$ & $6.4 \pm 0.6$ & $6.6 \pm 0.6$ \\
\hline
\end{tabular}

Intervention: 1-hour occlusion of superior mesenteric artery or cardiopulmonary bypass. CPB, Cardiopulmonary bypass; Vaso, vasopressin; Hct, hematocrit; ET-1, endothelin-1. $* P<.05$ vs sham. $\dagger P<.05$ vs baseline. $\ddagger P<.05$ vs CPB. $\S$ Difference between aortic and superior mesenteric vein.

In group II (mesenteric ischemia), postischemic reperfusion of the intestine was associated with a significant decrease in SVR and corresponding alterations in the cardiac output and mean arterial pressure compared with baseline $(P<.001)$ and group I $(P=.025$; Table 1$)$. Mesenteric blood flow $(P=.007)$ and cardiac output $(P=.04)$ were significantly increased throughout the reperfusion period (Figures 1 and 2).

In group III (CPB), the onset of CPB initiated a significant decrease in SVR, which remained below baseline and lower than that in group $\mathrm{I}(P=.005$; Figures 1 and 2 and Table 1$)$. Mesenteric blood flow and cardiac output remained constant during $\mathrm{CPB}$ and increased significantly compared with baseline during the post-CPB period $(P=.007$; Figures 1 and 2).

In group IV (CPB plus vasopressin), SVR remained constant during $\mathrm{CPB}$, with a gradual decrease after termination of CPB and discontinuation of vasopressin infusion. This decrease was significant at 30 minutes of reperfusion $(P=.02$; Figure 1). A significant decrease in mesenteric blood flow was observed during $\mathrm{CPB}$ compared with that at baseline $(P<.001)$ and in group III $(P=.01)$ and group $\mathrm{I}(P=.01)$. Mesenteric perfusion returned to baseline levels after termination of CPB (Figure 2).

\section{Microcirculation and Oxygen Saturation}

In group I, microvascular perfusion and oxygen saturation in the jejunal tissue remained constant (Figure 3 and Table 1). In group II, a significant decrease was seen in the microvascular blood flow $(P<.001)$ and oxygen saturation $(P<.001$; Figure 3 and Table 1$)$ during occlusion of the SMA. During reperfusion, fast recovery of oxygen saturation occurred within 2 minutes (Table 1) and microvascular flow slowly returned to baseline within 60 minutes (Figure 3).

In group III (CPB), the onset of CPB initiated a significant decrease of jejunal mucosal blood flow $(P=.025)$ and oxygen saturation $(P<.001$; Figure 2 and Table 1$)$. Mucosal flow remained less than that at baseline $(P=.047)$ and that in group I $(P=.05)$ until the end of the experiment (Figure 3).

In group IV (CPB plus vasopressin), jejunal microvascular flow and oxygen saturation remained constant during $\mathrm{CPB}$. After discontinuing CPB and vasopressin administration, mucosal flow decreased significantly compared with that at baseline $(P=.015)$ and in group I $(P=.031$; Figure 3$)$. Oxygen saturation remained greater than that at baseline after CPB for 60 minutes $(P=.023$; Table 1). 

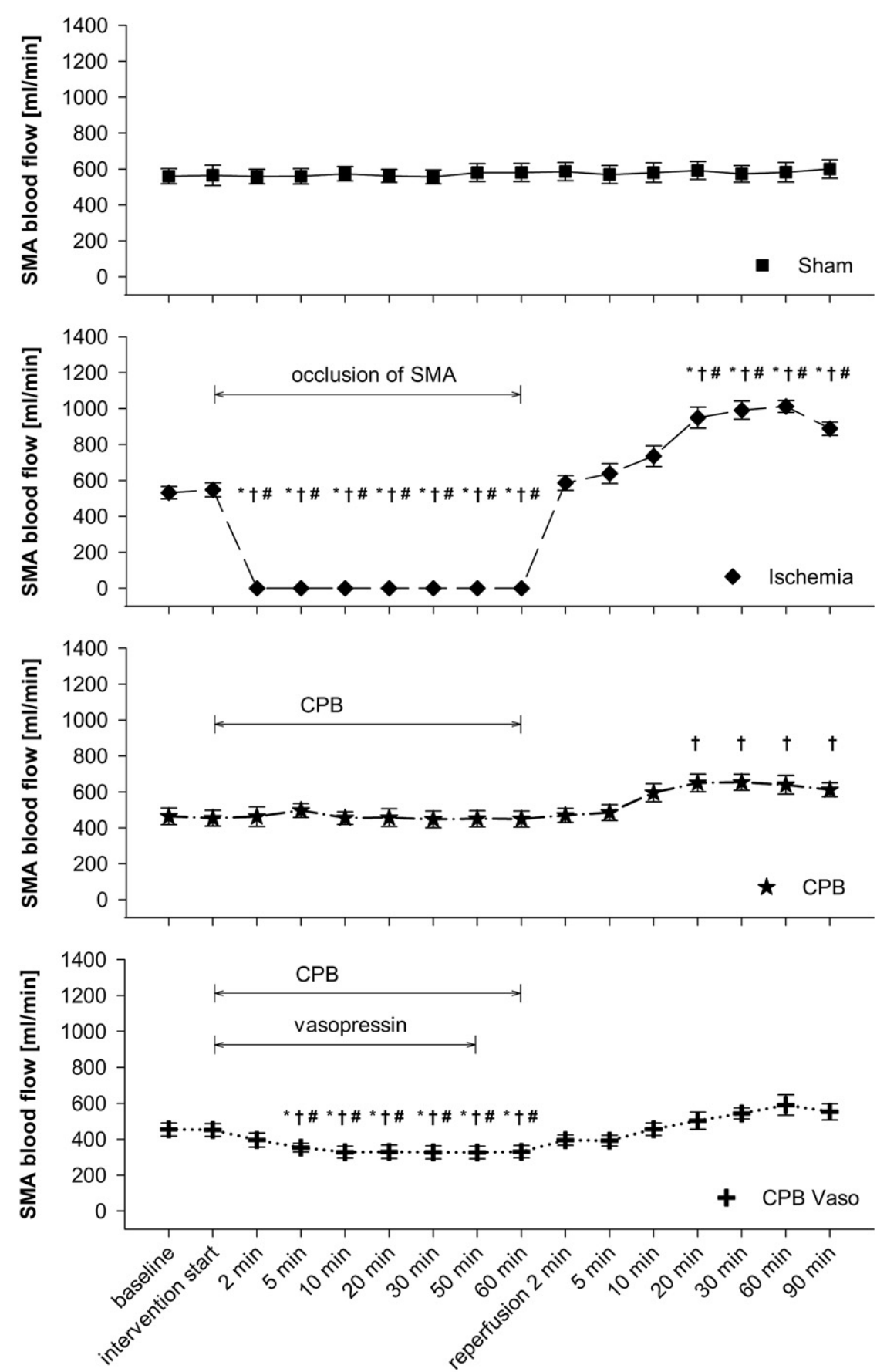

FIGURE 2. Superior mesenteric artery ( $S M A)$ blood flow. Intervention: 1 -hour occlusion of the SMA or cardiopulmonary bypass $(C P B)$. $* P<.05$ vs sham group; $\nmid P<.05$ vs baseline; $\# P<.05$ vs CPB group. Vaso, Vasopressin.

\section{Jejunal Capillary Density}

Intravital microscopy in group I revealed constant capillary density in the jejunum (Table 1). In group II, there was complete cessation of capillary blood flow (ie, loss of capillary density) during occlusion of the SMA $(P<.001)$. During reperfusion, the capillary density increased but did not recover to baseline or that of group I
(Table 1). In group III (CPB), the onset of CPB initiated a significant decrease in capillary density $(P=.005)$ that remained less than that at baseline $(P=.027)$ and in group I $(P<.001)$ until the end of the experiment (Figure 4 and Table 1). In group IV (CPB plus vasopres$\sin$ ), the jejunal capillary density remained constant during $\mathrm{CPB}(P=.1)$. After discontinuing vasopressin 

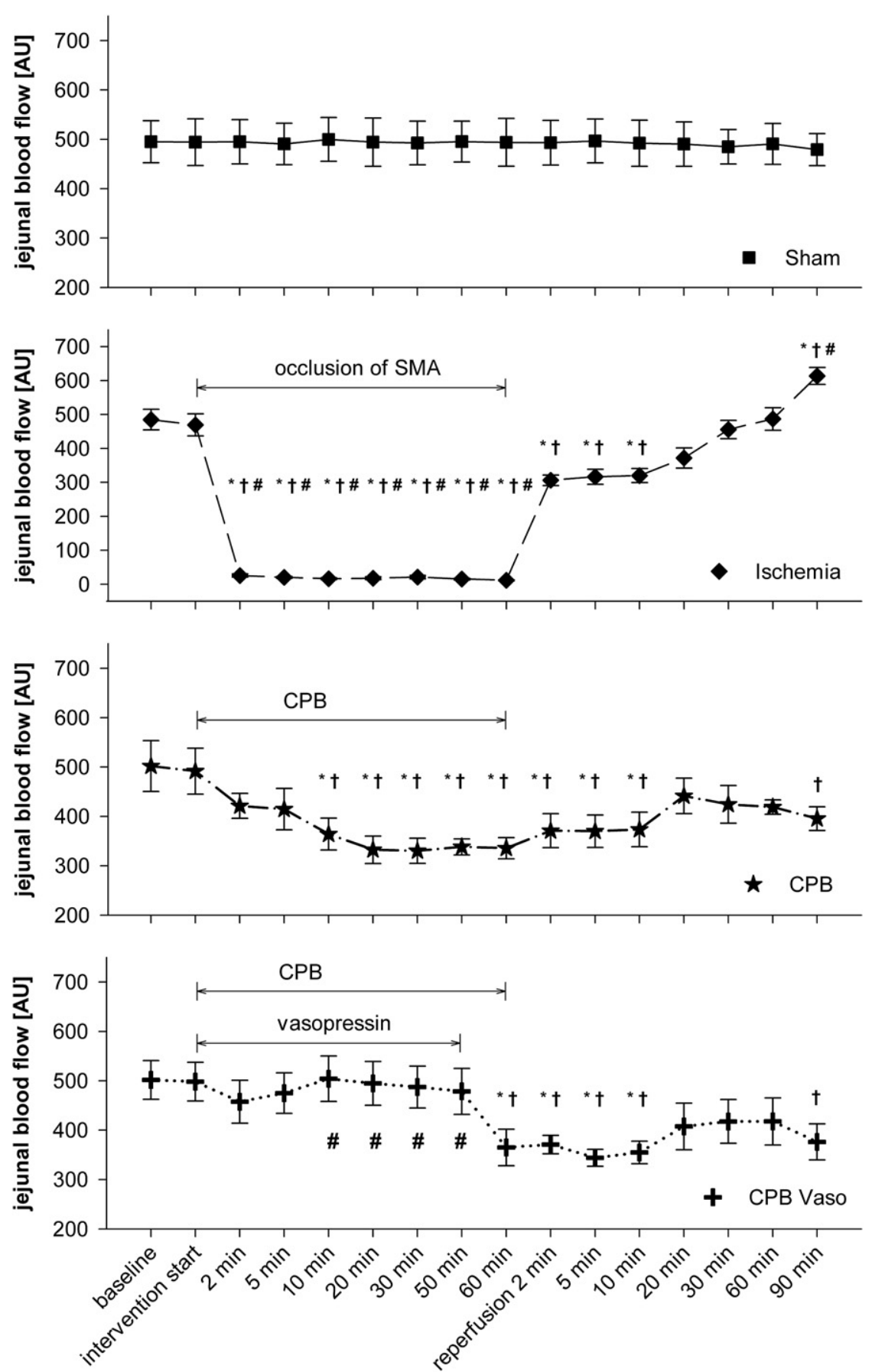

FIGURE 3. Distal jejunal mucosal blood flow. Intervention: 1-hour occlusion of the superior mesenteric artery ( $S M A)$ or cardiopulmonary bypass $(C P B)$. $* P<.05$ vs sham group; $\dagger P<.05$ vs baseline; $\# P<.05$ vs CPB group. Vaso, Vasopressin.

administration and CPB, the jejunal capillary density decreased significantly compared with that baseline and in group I $(P=.02$; Figure 4 and Table 1$)$.

\section{Blood Analysis}

In groups I and II, the hematocrit remained constant, but in groups III and IV, there was a significant reduction during CPB (Table 1). The mesenteric venous potassium level increased significantly during intervention only in group II. In groups I, III, and IV, the lactate concentration and arterial ET-1 levels remained constant throughout the experiment (Table 1). In group II, a significant increase in the lactate concentration $(P=.024)$ and ET-1 plasma level $(P<.001)$ was found during occlusion of the SMA. During 

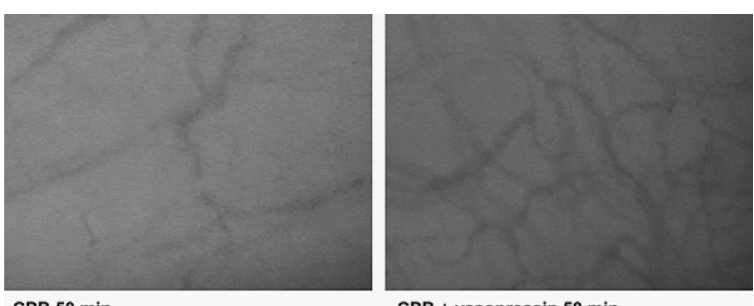

CPB $50 \mathrm{~min}$

$\mathrm{CPB}+$ vasopressin $50 \mathrm{~min}$

FIGURE 4. Intravital microscopy images in groups III (cardiopulmonary bypass $[C P B]$ for 50 minutes) and IV (CPB plus vasopressin for 50 minutes) after 50 minutes of intervention.

reperfusion, recovery to baseline occurred within $60 \mathrm{~min}$ utes (Table 1).

\section{Jejunal ET Gene Expression}

In group II, the jejunal gene expression of ET-1 was significantly elevated compared with that in group I at the end of the experiment $(P=.021$; Figure 5$)$.

In group III (CPB), the expression of ET-1 was significantly increased compared with that in groups I $(P=.006)$, II $(P=.01)$, and IV $(P=.004$; Figure 5). The expression of ET receptor $\mathrm{A}\left(\mathrm{ET}_{\mathrm{A}}\right)$ in this group was also significantly elevated compared with the expression in groups I $(P=.01)$, II $(P=.03)$, and IV $(P=.01)$. The expression of ET receptor $\mathrm{B}\left(\mathrm{ET}_{\mathrm{B}}\right)$ was only increased compared with that in group IV $(P=.03)$. In group IV, the expression of ET-1 and $\mathrm{ET}_{\mathrm{A}}$ and $\mathrm{ET}_{\mathrm{B}}$ was comparable to that in group I and thus significantly lower than that in group III $(P=.004, P=.01$, and $P=.03$, respectively).

\section{DISCUSSION}

Extracorporeal circulation leads to a systemic inflammatory response syndrome with hemodynamic changes most commonly involving vasodilation and the need for vasopressor treatment. ${ }^{1,2}$ More recently, a decrease in circulating vasopressin levels has been described during

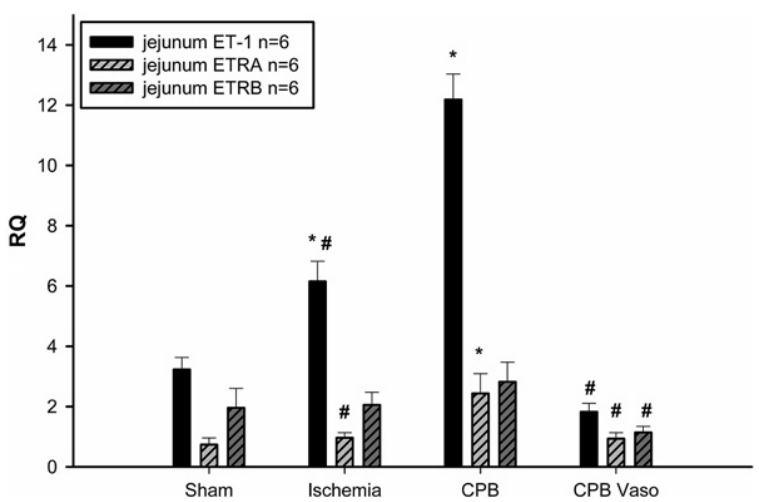

FIGURE 5. Jejunal gene expression of endothlin-1 (ET-1) and endothelin receptor subtypes $\mathrm{A}$ and $\mathrm{B}$ (ETRA and ETRB). A ratio of target tissue and muscle tissue was calculated. $* P<.05$ vs sham group. $\# P<.05$ vs cardiopulmonary bypass $(C P B)$. Vaso, Vasopressin.
CPB. ${ }^{15}$ Several studies have documented alterations in intestinal microcirculation during extracorporeal circulation. ${ }^{5,6,13,16}$ Postoperative nonocclusive mesenteric ischemia can occur; it is as yet unclear whether NOMI is simply the delayed result of microcirculatory alterations initiated during CPB or rather the manifestation of a separate disease. Alternatively, it can be assumed that the changes in the microcirculation are a consequence of the vasopressor treatment necessary in many patients during and after operations involving $\mathrm{CPB} .{ }^{6,15,17}$

To understand the pathomechanism of NOMI, it, therefore, appears necessary to study the physiologic response of the effect of mesenteric perfusion to $\mathrm{CPB}$. We decided to study intestinal blood flow on a macroscopic and microscopic level, because the microcirculation might not follow the regulation of global intestinal blood flow. As controls, we chose a group of animals without manipulation (apart from the instrumentation necessary for measurement of the parameters) and another group with surgical occlusion of the SMA.

During CPB, we maintained the pump flow at the level of the baseline cardiac output. As expected, the blood flow in the SMA was not affected by CPB in our experiments. The jejunal microcirculation, however, showed a pathologic response in line with that in previous studies. ${ }^{5,6,13}$ The decrease in jejunal microcirculation was not only seen by laser Doppler fluxmetry, but was also confirmed by intravital microscopy. The changes in jejunal microcirculation persisted until the end of the experiment. These observations indicate increased shunt perfusion at the cost of nutritive flow to the intestinal wall. Increased arteriovenous shunting has also been described in a previous study. ${ }^{18}$

Despite a decrease in total SMA blood flow during CPB and vasopressin administration, the jejunal microcirculation remained normal. Thus, the reduction in the macroscopic blood flow apparently did not have an adverse effect on tissue perfusion and oxygenation. We assume that the vasopressin administration in our model decreased shunt perfusion, possibly by increasing jejunal vascular resistance and leading to preserved jejunal microcirculation. Only after termination of CPB and vasopressin administration did we observe a decrease in jejunal capillary density and microvascular perfusion. This suggests that the lack of the vasopressin effect on the precapillary muscle tone resulted in increased shunt perfusion.

A significant increase in jejunal ET-1 expression and also increased arterial ET-1 was found in the ischemia group. Increased arterial ET-1 has also been described in a previous mesenteric ischemia study, ${ }^{4}$ as well as during CPB. ${ }^{19} \mathrm{~A}$ significant increase in jejunal ET-1 expression and increased $\mathrm{ET}_{\mathrm{A}}$ receptor expression were observed in the CPB group. These findings are in line with the demonstrated impaired jejunal microcirculation during CPB. They are also 
consistent with the mechanism of ET, because the $\mathrm{ET}_{\mathrm{A}}$ located on the vascular smooth muscle mediates vasoconstriction as a response to ET- $1 .{ }^{4,19} \mathrm{ET}_{\mathrm{A}}$ and $\mathrm{ET}_{\mathrm{B}}$ are $\mathrm{G}$ protein-coupled receptors, which have been shown to have a half-life of approximately 40 minutes. ${ }^{20}$ Thus, our findings of increased mRNA levels of both ET receptors appear plausible.

Vasopressin interacts with the ET system and has been reported to evoke ET-1 release from the perfused rat mesenteric vascular bed. ${ }^{21}$ Its clinical use has been reported to be safe in the context of CPB. ${ }^{15,17}$ In our experiments, the vasopressin administration during $\mathrm{CPB}$ did not alter the ET system. In contrast, ET-1, $\mathrm{ET}_{\mathrm{A}}$, and $\mathrm{ET}_{\mathrm{B}}$ remained normal, and the changes in the ET system were apparently obviated. In addition, vasopressin administration during extracorporeal circulation resulted in preserved jejunal microcirculation.

Our results in the vasopressin group-with normal $\mathrm{ET}_{\mathrm{A}}$ and $\mathrm{ET}_{\mathrm{B}}$ expression associated with normal jejunal microcirculation - are compatible with previous findings of a protective effect of ET receptor antagonists in ischemia/ reperfusion injury of the small bowel. ${ }^{4,22}$ Additionally, a recent study by Toole and colleagues ${ }^{23}$ proved the safety of $\mathrm{ET}_{\mathrm{A}}$ antagonist treatment in high-risk cardiac surgery patients. In line with this, the administration of ET-1 has been shown to result in reduced microvascular flow of the jejunum and ileum. ${ }^{24}$ These findings indicate that the ET system plays an active role in intestinal ischemia. The design of the present experiment did not allow us to determine the duration of the alterations in the ET system.

Our findings imply an interaction between the ET and vasopressin systems, although the investigation was not designed to clarify the possible mechanisms of interaction. The results also indicate that vasopressin could be a potent and physiologic vasopressor during and after $\mathrm{CPB} .{ }^{17}$ This is in line with another report that did not show a negative influence of vasopressin on jejunal mucosal blood flow. ${ }^{25}$

Because the study was performed in a porcine model, the results might not be directly transferable to humans. The number of pigs in each group was limited; however, efforts were made to keep temperature, left atrial pressure, and fluid balance constant. Thus, no significant differences were found in most of these parameters among the groups.

Additional investigations in patients with nonocclusive mesenteric ischemia after cardiac surgery are needed to determine the pathophysiologic role of plasma ET-1 levels. If ET-1 proves to be a major player in the development of NOMI after cardiac surgery, interventional studies elucidating the effect of ET-1 receptor antagonists should be performed. Regarding the potential protective effect of vasopressin in the treatment of vasodilatory shock after cardiac surgery, additional studies with hard endpoints are needed.

\section{CONCLUSIONS}

CPB leads to decreased tissue perfusion of the jejunum. This seems to be associated with marked upregulation of ET-1 and $\mathrm{ET}_{\mathrm{A}}$. Vasopressin given during $\mathrm{CPB}$ appears to maintain adequate distal jejunal mucosal perfusion during $\mathrm{CPB}$ and to prevent the alterations of the ET system.

We thank Doris Bandner-Risch, Elisabeth Gluding, Janine Becker, Matous Novak and Claudia Scheuer for support in the laboratory. Additionally, we thank Jürgen Priebe and Kai Hennemann for their support in using extracorporeal circulation.

\section{References}

1. Abboud B, Daher R, Boujaoude J. Acute mesenteric ischemia after cardiopulmonary bypass surgery. World J Gastroenterol. 2008;14:5361-70.

2. Christenson JT, Schmuziger M, Maurice J, Simonet F, Velebit V. Gastrointestinal complications after coronary artery bypass grafting. J Thorac Cardiovasc Surg. 1994;108:899-906.

3. Maier S, Hasibeder W, Pajk W, Hengl C, Ulmer H, Hausdorfer H, et al. Arginine-vasopressin attenuates beneficial norepinephrine effect on jejunal mucosal tissue oxygenation during endotoxinaemia. Br J Anaesth. 2009;103: 691-700.

4. Andersson A, Fenhammar J, Weitzberg E, Sollevi A, Hjelmqvist H, Frithiof R. Endothelin-mediated gut microcirculatory dysfunction during porcine endotoxaemia. Br J Anaesth. 2010;105:640-7.

5. O'Dwyer C, Woodson LC, Conroy BP, Lin CY, Deyo DJ, Uchida T, et al. Regional perfusion abnormalities with phenylephrine during normothermic bypass. Ann Thorac Surg. 1997;63:728-35.

6. Khan TA, Bianchi C, Ruel M, Feng J, Sellke FW. Differential effects on the mesenteric microcirculatory response to vasopressin and phenylephrine after cardiopulmonary bypass. J Thorac Cardiovasc Surg. 2007;133:682-8.

7. Hinohara H, Kadoi Y, Tokue A, Saito S, Kawauchi C, Mizutani A. Comparison of the effects of vasopressin and norepinephrine on organ perfusion during septic shock in streptozotocin-induced diabetic rats. J Anesth. 2010;24:553-63.

8. Schwarz B, Hofstotter H, Salak N, Pajk W, Knotzer H, Mayr A, et al. Effects of norepinephrine and phenylephrine on intestinal oxygen supply and mucosal tissue oxygen tension. Intensive Care Med. 2001;27:593-601.

9. Salak N, Pajk W, Knotzer H, Hofstotter H, Schwarz B, Mayr A, et al. Effects of epinephrine on intestinal oxygen supply and mucosal tissue oxygen tension in pigs. Crit Care Med. 2001;29:367-73.

10. Nygren A, Thoren A, Ricksten SE. Vasopressin decreases intestinal mucosal perfusion: a clinical study on cardiac surgery patients in vasodilatory shock. Acta Anaesthesiol Scand. 2009;53:581-8.

11. Hiltebrand LB, Krejci V, Jakob SM, Takala J, Sigurdsson GH. Effects of vasopressin on microcirculatory blood flow in the gastrointestinal tract in anesthetized pigs in septic shock. Anesthesiology. 2007;106:1156-67.

12. Malay MB, Ashton JL, Dahl K, Savage EB, Burchell SA, Ashton RC Jr, et al. Heterogeneity of the vasoconstrictor effect of vasopressin in septic shock. Crit Care Med. 2004;32:1327-31.

13. Tao W, Zwischenberger JB, Nguyen TT, Vertrees RA, McDaniel LB, Nutt LK, et al. Gut mucosal ischemia during normothermic cardiopulmonary bypass results from blood flow redistribution and increased oxygen demand. J Thorac Cardiovasc Surg. 1995;110:819-28.

14. Livak KJ, Schmittgen TD. Analysis of relative gene expression data using realtime quantitative PCR and the 2(-Delta Delta C(T)) method. Methods. 2001; 25:402-8.

15. Argenziano M, Chen JM, Choudhri AF, Cullinane S, Garfein E, Weinberg AD, et al. Management of vasodilatory shock after cardiac surgery: identification of predisposing factors and use of a novel pressor agent. J Thorac Cardiovasc Surg. 1998;116:973-80.

16. Khan TA, Bianchi C, Ruel M, Voisine P, Sellke FW. Mitogen-activated protein kinase pathways and cardiac surgery. J Thorac Cardiovasc Surg. 2004;127: 806-11.

17. Morales DL, Gregg D, Helman DN, et al. Arginine vasopressin in the treatment of 50 patients with postcardiotomy vasodilatory shock. Ann Thorac Surg. 2000;69: 102-6.

18. Bond JH, Levitt MD. Use of microspheres to measure small intestinal villus blood flow in the dog. Am J Physiol. 1979;236:E577-83. 
19. Bond BR, Dorman BH, Clair MJ, Williams MR, Naka Y, Landry DW, et al. Endothelin-1 during and after cardiopulmonary bypass: association to graft sensitivity and postoperative recovery. J Thorac Cardiovasc Surg. 2001;122: 358-64.

20. Kirigiti P, Bai Y, Yang YF, Li X, Li B, Brewer G, et al. Agonist-mediated downregulation of rat beta1-adrenergic receptor transcripts: role of potential posttranscriptional degradation factors. Mol Pharmacol. 2001;60:1308-24.

21. Tomobe Y, Yanagisawa M, Fujimori A, Masaki T, Goto K. Arginine-vasopressin increases the release of ET-1 into perfusate of rat mesenteric artery. Biochem Biophys Res Commun. 1993;191:654-61.

22. Lugowska-Umer H, Umer A, Sein-Anand J, Sokolowska-Wojdylo M, Wlodarkiewicz A, Korolkiewicz RP. Endothelin receptor blockers protect against ischemia/reperfusion impairment of gastrointestinal motility in rats. Pharmacol Res. 2008;57:413-8.

23. Toole JM, Ikonomidis JS, Szeto WY, Zellner JL, Mulcahy J, Deardorff RL, et al. Selective endothelin-1 receptor type A inhibition in subjects undergoing cardiac surgery with preexisting left ventricular dysfunction: influence on early postoperative hemodynamics. J Thorac Cardiovasc Surg. 2010;139:646-54.

24. Nankervis CA, Nowicki PT. Role of endothelin-1 in regulation of the postnatal intestinal circulation. Am J Physiol Gastrointest Liver Physiol. 2000;278: G367-75.

25. Liard JF, Deriaz O, Schelling P, Thibonnier M. Cardiac output distribution during vasopressin infusion or dehydration in conscious dogs. Am J Physiol. 1982;243: H663-9. 